\title{
A comparison of the engineering properties of gap-graded and well-graded road bituminous mixtures
}

\author{
I. Kamaruddin ${ }^{1}$, A. Soelistijo ${ }^{2}$ \& M. Napiah ${ }^{1}$ \\ ${ }^{I}$ Department of Civil Engineering, Universiti Teknologi PETRONAS, \\ Malaysia \\ ${ }^{2}$ Directorate General of Highways, Department of Public Works, \\ Indonesia
}

\begin{abstract}
The design of road pavement material seeks to obtain a durable, mechanically strong system that is able to resist dynamic traffic loadings without causing distresses to the pavement due to loading and environmental factors. In addition, the design of the material must consider the economics of construction and maintenance. Road bituminous materials as used worldwide normally are of gapgraded material (Hot-Rolled Asphalt) or well-graded material (Asphaltic Concrete). Both materials have advantages and disadvantages. This study attempts to compare the engineering properties of these two road materials. In addition, the workability of both materials will be assessed, which relates to the energy required in the production, handling and compaction of the mixtures. The durability of the material is a concern to engineers as the material is exposed to both air and water. This is reflected in the permeability of the material, which in this study is assessed by an air permeameter.
\end{abstract}

Keywords: gap graded, Hot-Rolled Asphalt (HRA), well-graded, asphaltic Concrete $(A C)$, workability, permeability.

\section{Introduction}

Road bituminous mixtures when used in a pavement structure have to fulfil a number of different requirements. They must be workable, have the ability to be satisfactorily compacted, be impermeable, be durable in resisting abrasion by 
traffic and the effect of air and water, provide a skid resistant surface under all weather conditions, resist permanent deformation and fatigue cracking by traffic loads and have the ability to be easily maintained Two types of road bituminous mixtures normally used worldwide are either the well graded Asphaltic Concrete or the gap graded Hot-Rolled Asphalt.

A laboratory study was carried out in order to evaluate the engineering properties of bituminous mixtures of different gradations. Two types of mixtures were prepared, namely Hot-Rolled Asphalt (HRA) and Asphaltic Concrete (AC) mixtures. The engineering properties were determined from the Marshall testing method commonly used in the testing of bituminous materials. In addition, the workability and air permeability characteristics of the mixtures were also determined using the Gyratory Testing Machine (GTM) and an air permeability apparatus.

\section{Hot-Rolled Asphalt (HRA) mixtures}

HRA is a gap-graded bituminous mixture that normally consists of bitumen which binds three separate and distinct sizes of aggregate, namely coarse aggregate, sand and filler. Since this mixture has little stone to stone contact in the compacted state, the mixtures are therefore made with relatively hard bitumen. The use of hard bitumen is aimed at making the mortar consisting of sand, filler and bitumen as stiff as possible [1]. The function of the stone is mainly to extend the mortar, thus making the mixture more economical. The gap-graded design makes HRA bituminous mixture display a weather resistant characteristic while providing a durable surface able to accommodate heavy traffic loads without cracking [2].

\section{Asphaltic Concrete (AC) mixtures}

AC bituminous mixtures consist of continuously graded aggregates, thus deriving its strength and stability primarily through aggregate interlock [2]. It was also ascertained in a previous study [1] that the properties of AC mixtures are partly influenced by the inter particle friction and interlocking of the aggregates and partly by the viscosity of the binder. The study also stated that the grading of the aggregates was very important for AC mixtures and demonstrated that at optimum bitumen content, the highest stabilities were achieved with those gradations possessing the highest compacted aggregate densities.

\section{Materials used and their properties}

Coarse aggregate in HRA mixtures is defined as aggregate which is substantially retained on a $2.36 \mathrm{~mm}$ sieve [3]. The coarse aggregate used in this study had a maximum size of $14 \mathrm{~mm}$ and was angular in nature and rough in surface texture.

The determination of the relative density of the coarse aggregate was carried out using two methods of testing namely the standard test method specified by 
BS812:Part2:1975 and by using a helium pycnometer. The British Standard method produced the apparent relative density, relative density on an oven dried basis or bulk relative density and relative density on a saturated surface dried basis. The helium pycnometer test provided only the apparent relative density. In addition, the British Standard test also produced the water absorption value for the aggregates.

The apparent relative density produced by the helium pycnometer test was slightly higher than that measured by BS 812:Part 2:1975 as the helium gas used in the test was able to penetrate the accessible voids in the aggregate surface far greater than that for water, thus producing lower measured volumes.

BS 594: Part 1: 1992 specifies that fine aggregate for HRA mixtures should substantially pass a $2.36 \mathrm{~mm}$ test sieve and consist of sand or fines produced by crushing coarse aggregate or a blend of them. In this study, natural sand was used as fine aggregate. As was the case for coarse aggregate, the relative density of fine sand was measured using both the British Standard method [2] as well as the helium pycnometer test. Results of the relative density and water absorption measurement for both the coarse and fine aggregates are presented in Table 1.

Filler is defined as material which substantially passes a $0.075 \mathrm{~mm}$ test sieve, added to the mixture in excess of that present in the proportioned coarse and fine aggregate [3]. The filler used in this study was limestone dust with an apparent relative density measured from the helium pycnometer test and presented in Table 1 .

Table 1: $\quad$ Properties of coarse and fine aggregates and filler for Hot-Rolled Asphalt.

\begin{tabular}{|c|c|c|c|}
\hline Aggregate & Property & $\begin{array}{c}\text { BS 812: } \\
\text { Part 2:1975 }\end{array}$ & $\begin{array}{c}\text { Helium } \\
\text { Pycnometer }\end{array}$ \\
\hline \multirow{4}{*}{$\begin{array}{l}\text { Coarse } \\
\text { Aggregate } \\
14 \mathrm{~mm}\end{array}$} & Apparent Relative Density & 2.92 & 2.93 \\
\hline & $\begin{array}{l}\text { Relative Density on an Oven } \\
\text { Dried Basis }\end{array}$ & 2.84 & \\
\hline & $\begin{array}{c}\text { Relative Density on a } \\
\text { Saturated Surface Dried } \\
\text { Basis }\end{array}$ & 2.87 & \\
\hline & Water Absorption (\%) & 0.87 & \\
\hline \multirow{4}{*}{$\begin{array}{l}\text { Fine } \\
\text { Aggregate } \\
\text { (Sand) }\end{array}$} & Apparent Relative Density & 2.66 & 2.67 \\
\hline & $\begin{array}{c}\text { Relative Density on an Oven } \\
\text { Dried Basis }\end{array}$ & 2.60 & \\
\hline & $\begin{array}{c}\text { Relative Density on a } \\
\text { Saturated Surface Dried } \\
\text { Basis } \\
\end{array}$ & 2.62 & \\
\hline & Water Absorption (\%) & 0.86 & \\
\hline $\begin{array}{c}\text { Filler } \\
\text { (Limestone } \\
\text { Dust) } \\
\end{array}$ & & & 2.72 \\
\hline
\end{tabular}


Table 2: Properties of 50 pen grade bitumen for Hot-Rolled Asphalt mixtures.

\begin{tabular}{|l|c|}
\hline \multicolumn{1}{|c|}{ Property } & Observed Value \\
\hline Penetration $(0.1 \mathrm{~mm})$ at $25^{\circ} \mathrm{C}$ & 50 \\
\hline Softening Point $(\mathrm{R} \& \mathrm{~B})\left({ }^{\circ} \mathrm{C}\right)$ & 50.4 \\
\hline Specific Gravity at $25^{\circ} \mathrm{C}$ & 1.028 \\
\hline Penetration Index & -1.1 \\
\hline
\end{tabular}

Table 3: Aggregate blending calculation for HRA type F wearing course designation 30/14 (BS 594:Part 1:1992).

\begin{tabular}{|c|c|c|c|c|c|c|c|c|}
\hline \multirow{2}{*}{$\begin{array}{l}\text { Sieve } \\
\text { Size } \\
(\mathrm{mm})\end{array}$} & \multicolumn{3}{|c|}{$\begin{array}{c}\text { Cumulative Passing } \\
(\%)\end{array}$} & \multicolumn{3}{|c|}{$\begin{array}{c}\text { Cumulative Passing } \\
(\%)\end{array}$} & \multirow{2}{*}{$\begin{array}{c}\text { Combined } \\
\text { Cumulative } \\
\text { Passing }\end{array}$} & \multirow[t]{2}{*}{$\begin{array}{l}\text { Spec. } \\
\text { Limit }\end{array}$} \\
\hline & Coarse & Fine & Filler & $\begin{array}{c}33 \% \\
\text { Coarse }\end{array}$ & $\begin{array}{l}57 \% \\
\text { Fine }\end{array}$ & $\begin{array}{l}10 \% \\
\text { Filler }\end{array}$ & & \\
\hline 20 & 100 & 100 & 100 & 33.00 & 57.00 & 10.00 & 100.00 & 100 \\
\hline 14 & 91.8 & 100 & 100 & 30.29 & 57.00 & 10.00 & 97.29 & $\begin{array}{l}85- \\
100\end{array}$ \\
\hline 10 & 27.12 & 100 & 100 & 8.95 & 57.00 & 10.00 & 75.95 & $\begin{array}{c}60- \\
90\end{array}$ \\
\hline 2.36 & 0 & 97.66 & 100 & 0.00 & 55.67 & 10.00 & 65.67 & $\begin{array}{l}60- \\
72 \\
\end{array}$ \\
\hline 0.600 & 0 & 89.36 & 100 & 0.00 & 50.94 & 10.00 & 60.94 & $\begin{array}{c}45- \\
72\end{array}$ \\
\hline 0.212 & 0 & 40.96 & 100 & 0.00 & 23.35 & 10.00 & 33.35 & $\begin{array}{c}15- \\
50\end{array}$ \\
\hline 0.075 & 0 & 1.3 & 100 & 0.00 & 0.74 & 10.00 & 10.74 & $8-12$ \\
\hline
\end{tabular}

As the strength of the HRA mixtures is derived from the stiffness of the mortar, a harder grade bitumen is recommended for use in these mixtures. 50 pen grade bitumen was used in this study to fabricate the HRA mixtures for normal traffic loading [3]. The properties of the bitumen used are listed in Table 2.

\section{Combined aggregate gradation}

Hot-Rolled Asphalt designation 30/14 type F wearing course was utilized in preparing the HRA specimens in this study [3]. In order to fit the HRA gradation, the coarse aggregate, the fine aggregate and the filler were combined in the following proportions: $33 \%$ coarse aggregate, 57\% fine aggregate and $10 \%$ filler. Table 3 presents the calculation of the combined aggregate gradation.

Crushed limestone coarse aggregates were used to prepare the AC specimens. The aggregates were angular in shape and had a rough surface texture. The coarse aggregate used was screened and separated into four different fractions i.e. $10 \mathrm{~mm}, 6.3 \mathrm{~mm}, 5 \mathrm{~mm}$ and $2.36 \mathrm{~mm}$. Both the British Standard test method 
[7] and the helium pycnometer were carried out to measure the relative density of the coarse aggregate.

Crushed gritstone fine aggregate was used to prepare the $\mathrm{AC}$ mixtures. The crushed gritstone was screened and separated into $1.18 \mathrm{~mm}$ fractions, $0.60 \mathrm{~mm}$ fractions and $0.075 \mathrm{~mm}$ fractions. The properties of the coarse and fine aggregate used are showed in Table 4. The same limestone powder filler material as used in preparing the HRA mixtures was used in the preparation of the AC mixtures.

100 pen grade bitumen was used in the AC mixtures. BS 3690: Part 1:1989 specifies that 100 pen bitumen should possess penetration values at $25^{\circ} \mathrm{C}$ of $100 \pm 20$ and a softening point value of $41^{\circ} \mathrm{C}$ to $51^{\circ} \mathrm{C}$. Table 5 present the properties of the bitumen used for the AC mixtures.

Table 4: $\quad$ Properties of the coarse and fine aggregate for the AC mixtures.

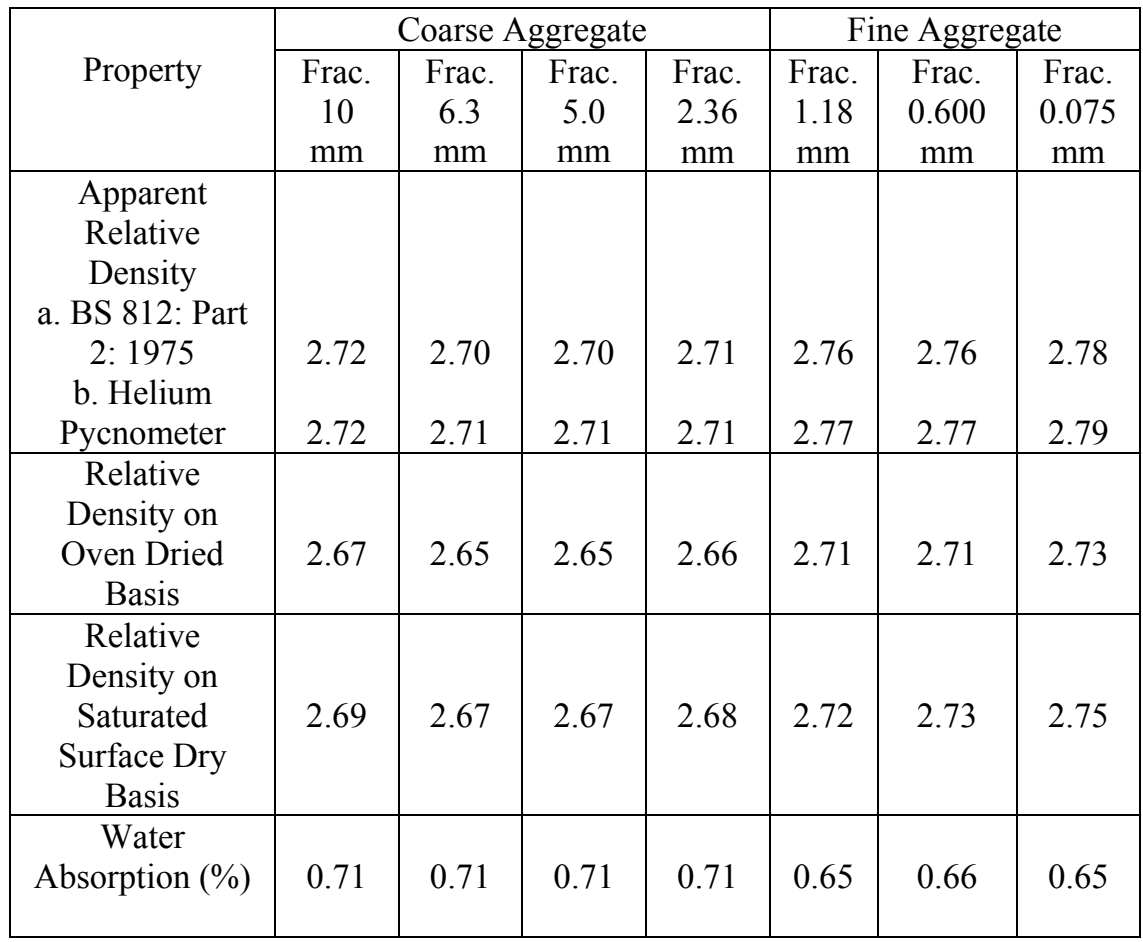

Table 5: $\quad$ Properties of bitumen used for the AC mixtures.

\begin{tabular}{|c|c|}
\hline Property & Observed Value \\
\hline Penetration $(0.1 \mathrm{~mm})$ at $25^{\circ} \mathrm{C}$ & 99 \\
\hline Softening Point $(\mathrm{R} \& \mathrm{~B})\left({ }^{\circ} \mathrm{C}\right)$ & 44.3 \\
\hline Specific Gravity at $25^{\circ} \mathrm{C}$ & 1.026 \\
\hline Penetration Index & -1.045 \\
\hline
\end{tabular}


Table 6: $\quad$ Aggregate grading for the AC mixtures.

\begin{tabular}{|c|c|}
\hline Sieve Size $(\mathrm{mm}$ & Percent Passing by Weight \\
\hline 14 & 100 \\
\hline 10 & 90.97 \\
\hline 6.3 & 77.42 \\
\hline 5.0 & 62.37 \\
\hline 2.36 & 49.82 \\
\hline 1.180 & 40.86 \\
\hline 0.600 & 26.20 \\
\hline 0.075 & 10.0 \\
\hline
\end{tabular}

Table 7: Compaction energy parameters for the GTM and Marshall Hammer (Cabrera [4]).

\begin{tabular}{|c|c|c|c|c|}
\hline $\begin{array}{c}\text { Compaction } \\
\text { Level }\end{array}$ & $\begin{array}{c}\text { Axial } \\
\text { Pressure } \\
\mathrm{MPa}\end{array}$ & $\begin{array}{c}\text { Gyratory } \\
\text { angle } \\
\left({ }^{\mathbf{o}}\right)\end{array}$ & $\begin{array}{c}\text { Number of } \\
\text { Revolutions }\end{array}$ & $\begin{array}{c}\text { Marshall } \\
\text { Hammer: } \\
\text { Number of } \\
\text { blows per side }\end{array}$ \\
\hline Normal & 0.7 & 1 & 30 & 50 \\
\hline Heavy & 1.4 & 1 & 30 & 70 \\
\hline
\end{tabular}

The coarse and fine aggregate that had been screened and separated into different fractions were recombined to meet the $\mathrm{AC}$ grading curve and is presented in Table 6.

\section{Experimental procedure}

The Gyratory Testing Machine (GTM) was employed to compact all the specimens. The development and characteristics of the GTM compactor was fully described elsewhere [4]. The GTM compactor was developed with the aim of simulating more realistically the action of the roller during compaction in the field. The GTM produced compaction within the specimen by a combination of static axial pressure and gyratory kneading. Table 7 presents the compaction energy parameter for the gyratory compactor compared with those of the usual Marshall hammer used for compacting bituminous material. Workability of the different mixtures was determined using the GTM during the compaction process.

The optimum bitumen content for the mixture was later determined. Five testing binder contents for each mix type were applied. The air permeability and the Marshall Stability tests were also conducted. The air permeability test was carried out using an Air Permeameter which involves a non-destructive test where the specimens tested could be reused in further tests. The detail description of the test can be found elsewhere [5]. 


\section{Engineering properties}

In order to determine the engineering properties of the mixtures i.e. bulk density, compacted aggregate density, void in mineral aggregates, void in mix and void filled with bitumen etc, the specimens were weighed in air and in water with the specimens exact dimensions being registered. The recoding of the sample heights was also carried out and will later be used in the calculation of workability, mix stiffness, Marshall Stability and permeability of the specimens.

Marshall Stability test was conducted in accordance to BS 594 (1992). Both stability and flow values were measured in this test. Stability is defined as the maximum load the specimens will carry before failure whereas flow is the amount of deformation before failure occurs [2]. Marshall Stability values are dependent upon the specimens' thicknesses, thus the stability values obtained were adjusted to the stability values of a standard specimen of height $63.5 \mathrm{~mm}$.

In general, the $\mathrm{AC}$ mixtures produced higher stability values than those of Hot-Rolled Asphalt. Although the HRA mixtures were produced using harder bitumen, the optimum stability value achieved was $9.48 \mathrm{kN}$ whereas the $\mathrm{AC}$ specimens, which were prepared using softer bitumen, exhibited an optimum stability value of $13.22 \mathrm{kN}$. This is because the aggregate interlock developed by the continuous grading of the AC mixtures contributes to a higher stability and in this study was enhanced by the use of crushed aggregate in the preparation of the samples.

Whilst the flow values were not used in the determination of the optimum binder content, the ensuing Marshall Quotient i.e. ratio of Marshall stability and flow can be used as a measure of the stiffness of the material and hence it's resistance to deformation [2]. It was noticed that in both mixtures, the flow values increased as the binder content is increased. Deformation in the mixtures is related to that of the mortar. Whilst the AC (using softer bitumen) had a lower optimum bitumen content (obc) as opposed to the HRA mixtures (using harder bitumen) which had a higher obc, it can be seen that the deformation is more pronounced in the AC mixtures. This may be due to the stiffer and more viscous mortar of the HRA making the mixture less deformation prone. The stiffness of the mixtures (given by the Marshall Quotient values) increased as the binder content increased. This is due to the lubricating effect of the binder which leads to a better compaction and stability of the mixtures. However, as the binder content is further increased, the stiffness decreased as the point of contacts between the aggregates is lost when the grains become separated by the excess volume of bitumen [1].

\section{Workability of bituminous mixtures}

The workability of bituminous mixtures depend on a number of factors including aggregate type, binder content and its viscosity and the temperature of mixing and compaction. Cabrera [4] argued that the measurement of resistance to mixing proposed above is better suited to systems which exhibit lower viscosities for compaction of bituminous mixtures. Accordingly, he developed a new approach 
to measure the workability of bituminous mixtures based on the experimental relation that exists between energy of compaction and porosity of the mixture. Cabrera [4] defined workability as the property which allows the production, handling and compaction of a mix with minimum application of energy. He explained that to quantify workability, the Gyratory Testing Machine (GTM) is utilized. During compaction of the bituminous specimen, the height reduction of the specimen is registered by reading a dial gauge attached to the lower ram of the machine at five revolutions intervals. These heights are used to calculate the volume of the specimen at 5,10,15,20, 25 and 30 revolutions. After cooling, the specimens are extruded from the mould and weighed and the data obtained together with the specimen volume are used to calculate the porosities of the specimen at different levels of gyratory compaction. A graph is then plotted relating the porosity at $\mathrm{i}$ number of revolutions $\left(\mathrm{P}_{\mathrm{i}}\right)$ to $\log$ of the number of revolutions (log i). Cabrera [4] stated that the experimental points should approximate a linear relation of the form:

$$
P_{i}=A-b(\log i)
$$

where $\mathrm{A}$ and $\mathrm{b}$ are constants of the regression line.

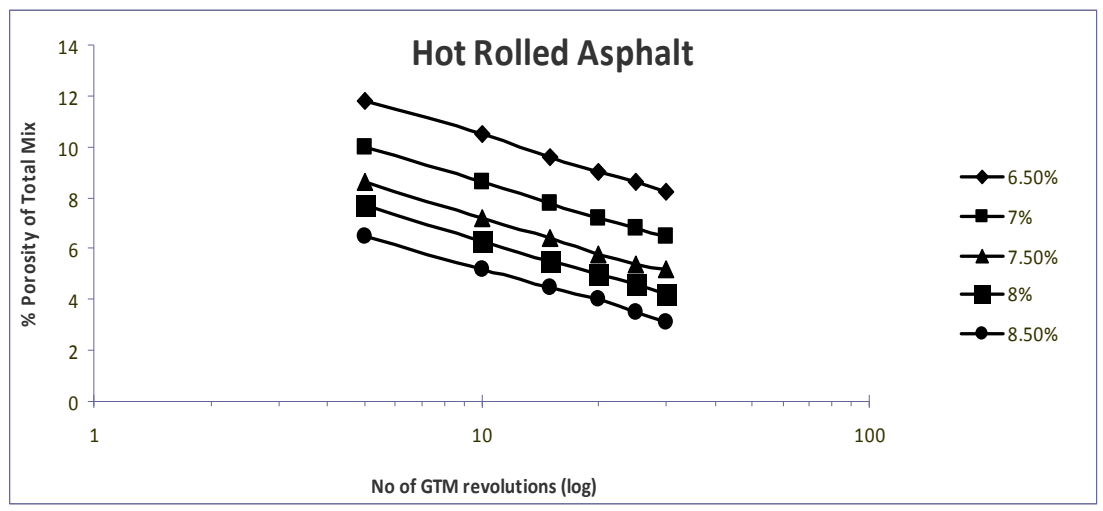

Figure 1: $\quad$ Porosity versus number of GTM revolutions for HRA mixtures.

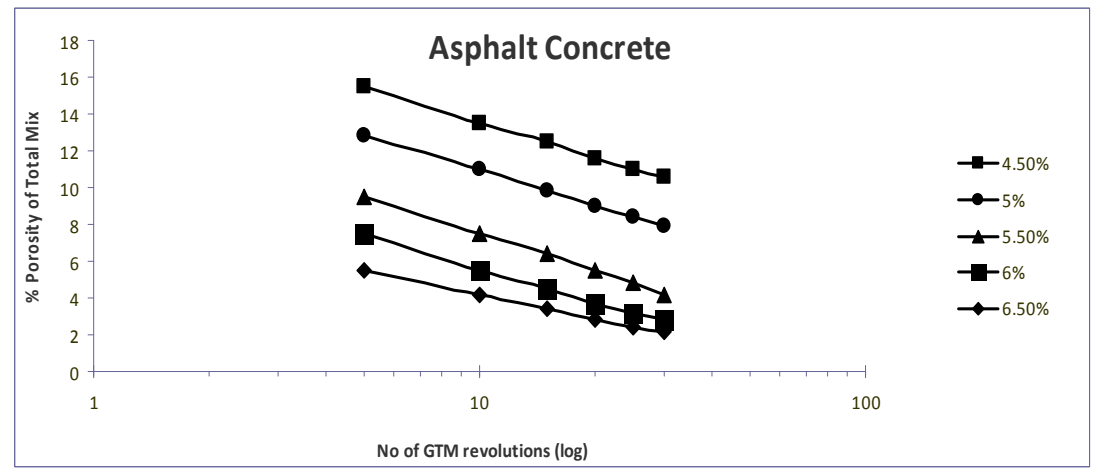

Figure 2: $\quad$ Porosity versus number of GTM revolutions for AC mixtures. 


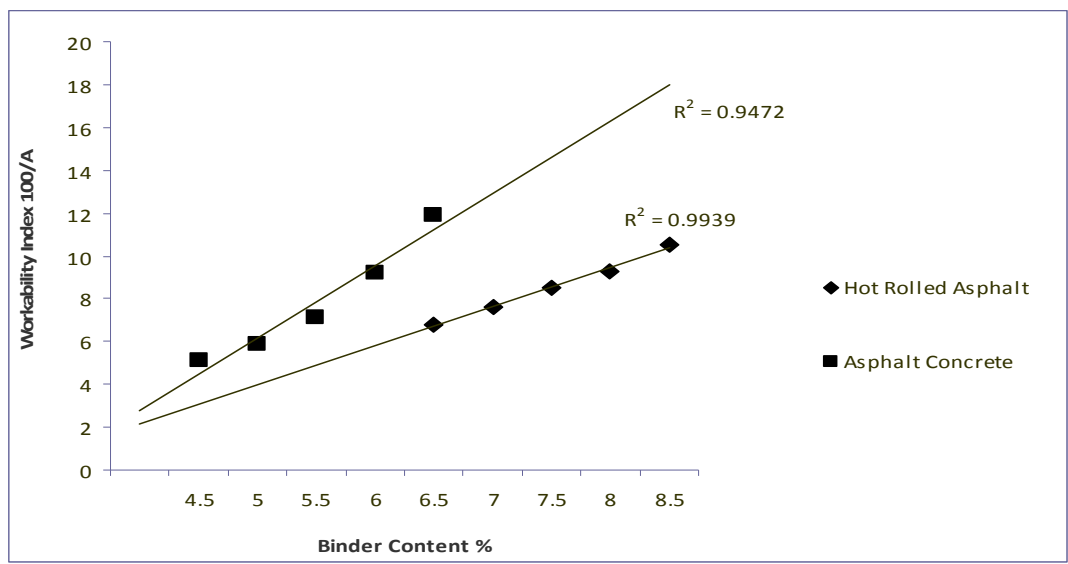

Figure 3: Graph of workability index versus binder content for HRA and AC mixtures.

Table 8: $\quad$ Summary of Marshall stability results.

\begin{tabular}{|c|c|c|c|c|}
\hline Mixture Type & $\begin{array}{c}\text { Binder } \\
\text { Content (\%) }\end{array}$ & Stability (kN) & Flow (mm) & $\begin{array}{c}\text { Marshall } \\
\text { Quotient } \\
(\mathrm{kN} / \mathrm{mm})\end{array}$ \\
\hline Hot-Rolled & 6.5 & 7.22 & 3.75 & 1.93 \\
Asphalt & 7.0 & 8.02 & 3.83 & 2.09 \\
(HRA) & 7.5 & 9.48 & 3.88 & 2.44 \\
& 8.0 & 8.57 & 4.00 & 2.14 \\
& 8.5 & 8.5 & 4.75 & 1.79 \\
\hline Asphaltic & 4.5 & 9.85 & 3.75 & 2.63 \\
Concrete & 5.0 & 10.87 & 4.10 & 2.65 \\
(AC) & 5.5 & 13.22 & 4.57 & 2.89 \\
& 6.0 & 10.42 & 5.30 & 1.97 \\
& 6.5 & 9.61 & 5.80 & 1.66 \\
\hline
\end{tabular}

Figures 1 and 2 show a relationship between the number of GTM revolutions and porosity for HRA and AC concrete mixtures respectively.

A graph relating the workability index results and binder content clearly shows that the workability index and bitumen content have a high linear correlation and is presented in Figure 3. The figure shows that in general the workability index increases as the bitumen content is increased. The slope of the line demonstrates the effect of change in bitumen content on the workability index values, the greater the slope the more noticeable the effect of binder content changes on the workability index values.

Other conclusions that can be drawn from the figure indicate that HRA mixtures fabricated in this work had workability indices of more than six (6), indicating that the mixtures were easy to mix and compact whereas the $\mathrm{AC}$ mixtures had workability values lower than six (6) at lower binder contents 
(4.5\% and 5.0\%), thus showing that the mixtures were more difficult to mix and compact. This can be attributed to the fact that these mixtures were manufactured using crushed aggregates causing harsh mixtures especially at the lower binder contents. In general, HRA mixtures had better workability than AC mixtures. Table 8 gives a summary of the Marshall Stability results from the two types of mixtures.

\section{Permeability of bituminous mixtures}

When designing a bituminous mixture, it is of great importance to ensure that the mixture should be resistant to the damaging effects of air and water. The presence of a large percentage of interconnected air voids which are permeable to the atmosphere permits the ingress of air and water into the mix which will simultaneously oxidize the exposed bitumen and weaken the adhesion between the bitumen film and the aggregates, thus weakening the mix. It is generally recognized that the durability of a bituminous pavement greatly depends upon its permeability.

Table 9: Bituminous mixtures in terms of permeability (after Davies and Walker [9]).

\begin{tabular}{|c|c|}
\hline Permeability, $\mathrm{K}\left(\mathrm{cm}^{2}\right)$ & Bituminous Mixture Class \\
\hline $10^{-14}-10^{-11}$ & Impervious \\
$10^{-11}-10^{-9}$ & Partially Impervious \\
$10^{-9}-10^{-7}$ & Poor Drainage \\
$10^{-7}-10^{-6}$ & Fair Drainage \\
$10^{-6}-10^{-3}$ & Good Drainage \\
\hline
\end{tabular}

Table 10: Permeability values at different binder contents for HRA and AC mixtures.

\begin{tabular}{|c|c|c|c|}
\hline Mixture Type & $\begin{array}{c}\text { Binder Content } \\
(\%)\end{array}$ & $\begin{array}{c}\text { Permeability K } \\
\left(\mathrm{cm}^{2}\right)\end{array}$ & $\begin{array}{c}\text { Coefficient of } \\
\text { Permeability k } \\
(\mathrm{cm} / \mathrm{sec})\end{array}$ \\
\hline Hot-Rolled & 6.5 & $8.59 \times 10^{-11}$ & $8.59 \times 10^{-6}$ \\
Asphalt (HRA) & 7.0 & $4.39 \times 10^{-11}$ & $4.39 \times 10^{-6}$ \\
& 7.5 & $2.30 \times 10^{-11}$ & $2.30 \times 10^{-6}$ \\
& 8.0 & $1.38 \times 10^{-11}$ & $1.38 \times 10^{-6}$ \\
& 8.5 & $1.20 \times 10^{-11}$ & $1.20 \times 10^{-6}$ \\
\hline Asphaltic & 4.5 & $3.71 \times 10^{-8}$ & $3.71 \times 10^{-3}$ \\
Concrete (AC) & 5.0 & $2.05 \times 10^{-8}$ & $2.05 \times 10^{-3}$ \\
& 5.5 & $4.90 \times 10^{-9}$ & $4.90 \times 10^{-4}$ \\
& 6.0 & $1.71 \times 10^{-9}$ & $1.71 \times 10^{-4}$ \\
& 6.5 & $1.36 \times 10^{-9}$ & $1.36 \times 10^{-4}$ \\
\hline
\end{tabular}


Davies and Walker [9] conducted an investigation on the permeability of a variety of asphalt mixtures. From their work, they proposed a classification of materials according to their permeability values $(\mathrm{K})$ in order to assess mixtures ranging from impervious to mixes with good drainage properties. This classification is presented in Table 9.

The air permeability test conducted in this study used an Air Permeameter. Description of the apparatus and the test procedure can be found elsewhere [6]. The test results are summarized in Table 10.

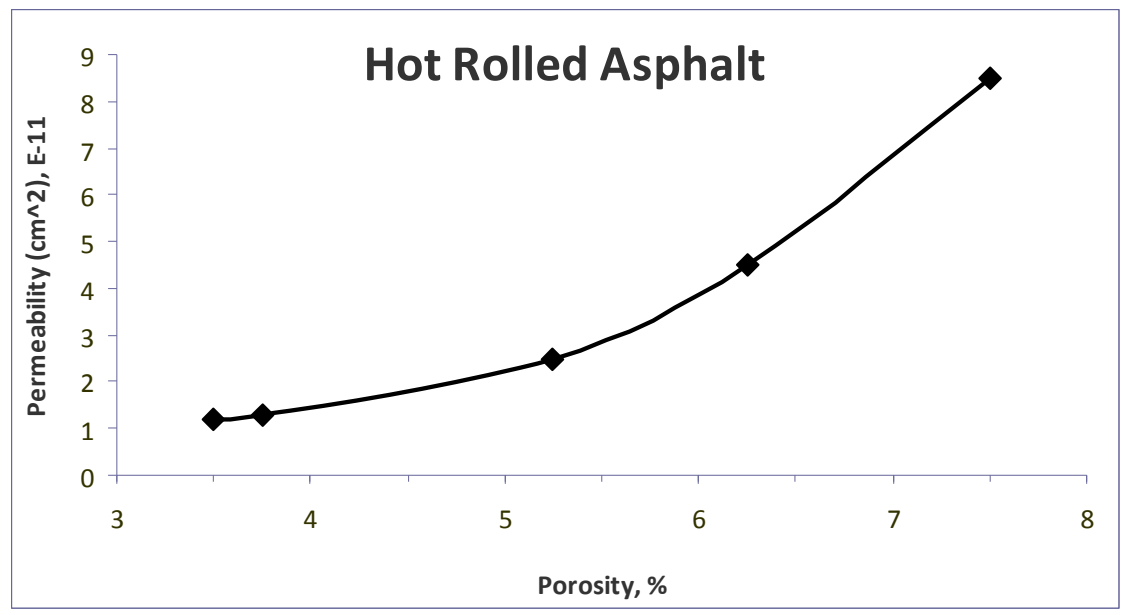

Figure 4: Relationship between permeability and porosity for HRA mixtures.

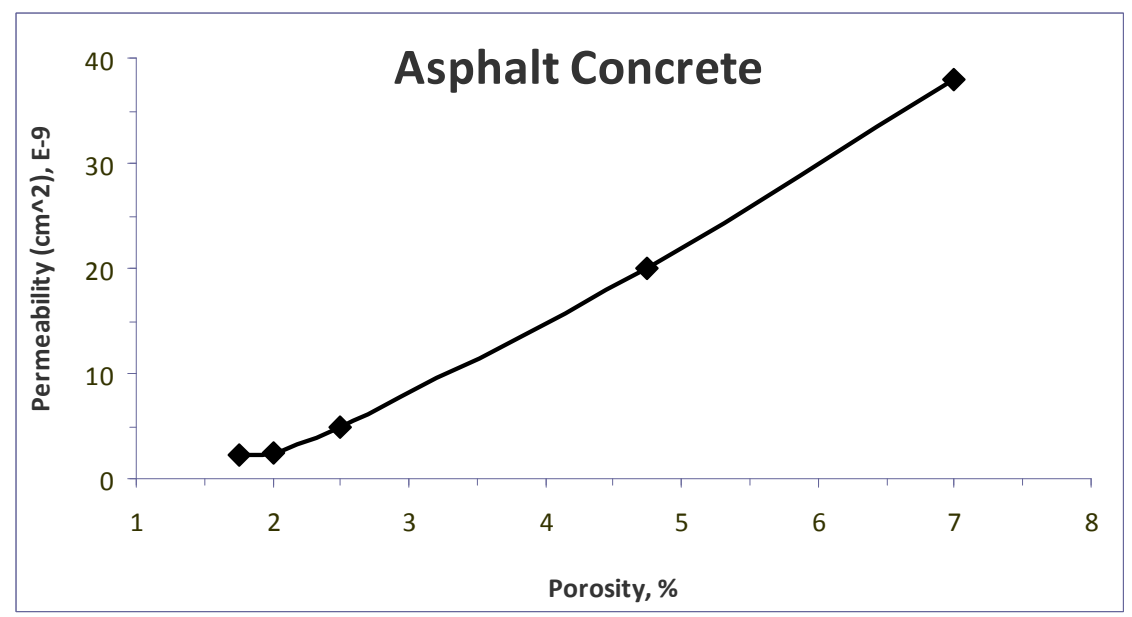

Figure 5: Relationship between permeability and porosity for AC mixtures. 
Table 10 indicates the manner in which the binder content influences the permeability values of bituminous mixtures. The results show that the higher the binder content, the lower the permeability values or the more impermeable the mixture becomes. From this trend, it can be concluded that the binder content is one of the major factors influencing the permeability of bituminous mixtures.

Figure 4 and Figure 5 demonstrate how porosity influences permeability. It can be noted that the permeability values increased with increasing porosity. The figure also shows that HRA produced lower permeability than those of AC. This was supported by the fact that in the determination of the workability index during compaction, HRA had a better workability than those of AC. Cabrera [4] stated that bituminous mixtures with low workability are poorly compacted, are more porous and permeable.

\section{Conclusion}

1. The Gyratory Testing Machine (GTM) proved a very simple equipment in measuring the workability of bituminous mixtures. The test conducted was rapid and the method used was able to differentiate the different workability of the different mixtures. Hot-Rolled Asphalt mixtures produced better workability than those of the Asphaltic Concrete mixtures. The effect of binder on the workability index of the bituminous mixtures clearly demonstrated that the higher the bitumen content, the higher is the corresponding workability index.

2. Although the Hot-Rolled Asphalt mixtures were produced using harder bitumen, they produced lower stability values than those of the Asphaltic Concrete, indicative that the strength of the Asphaltic Concrete is derived mainly through the aggregate interlock within the specimen.

3. The Air Permeameter apparatus used demonstrated its effectiveness in measuring the permeability characteristics of different bituminous mixtures types. The permeability test results showed that the Hot-Rolled Asphalt specimens exhibited lower permeability values compared to those of the Asphaltic Concrete, indicating that the Hot-Rolled Asphalt mixtures are more impermeable than the Asphaltic Concrete mixtures.

\section{References}

[1] Brien D., "Asphalt Mix Design, Development in Highway Pavement Engineering 1, edited by Peter S. Pell, pp. 93-125, London, 1978.

[2] Shell, "The Shell Bitumen Handbook", Shell Bitumen UK, 1992

[3] British Standard Institution, BS 594:Part 1:1992, "Hot-Rolled Asphalt for Roads and Other Paved Areas", BSI, London, 1992.

[4] Cabrera, J.G., "Assessment of the Workability of Bituminous Mixtures", Journal of Highways and Transportation, Vol. 38, No. 11, pp. 17-23, 1991.

[5] Cabrera, J.G. and Hassan TQM, "Quality Control During Construction of Bituminous Mixtures Using a Simple Air Permeameter Test”, Proceedings 
of the First National Conference on Bituminous Mixtures, Thessaloniki, Greece, 1992.

[6] Soelistijo A., "Stability and Tensile Strength of Bituminous Mixtures", Unpublished MSc Thesis, University of Leeds, 1995.

[7] British Standard Institution, BS 812:Part 2:1975, "Testing Aggregate, Method for Determination of Physical Properties", BSI, London, 1975.

[8] British Standard Institution, BS 3690:Part 1:1989, "Bitumen for Building and Civil Engineering, Part 1, Specification for Bitumen for Road and Other Paved Areas", BSI, London, 1989.

[9] Davies, J.R. and Walker R.N., "An Investigation on the Permeability of Asphalt Mixes", Ontario Joint Highway Research Programme No. RR145, Department of Highway, Ontario, Canada, 1969. 